\title{
Narrativas da docência: dimensão sensível do trabalho de professores e pesquisadores ${ }^{\star}$
}

\author{
Maria Elizabeth Barros de Barros, ${ }^{\text {Orid, } \star \star}$ Janaina Madeira Brito, ${ }^{\text {Orcid }}$ Ozilene Pereira Clemente ${ }^{\text {Orcid }}$ \\ Universidade Federal do Espírito Santo, Vitória, ES, Brasil
}

\begin{abstract}
Resumo
O artigo traz fios de uma experiência na iniciação científica em Psicologia, onde a vida na docência, o cotidiano e o trabalho na Educação se expressam nas narrativas produzidas pela pesquisadora e professores. Trata-se da experimentação da narrativa, inspirada no pensamento do filósofo Walter Benjamin, como metodologia de aproximação ao campo do trabalho na Educação. A narratividade é uma modalidade de pesquisa-intervenção, que produz um campo de afetos entre pesquisador-campo, resultando uma contribuição situada para a formação do pesquisador. Intercessores da Clínica da Atividade francesa e da Psicologia Institucional entram no diálogo sobre o trabalho em escola. Esta experiência traz a perspectiva sensivel para o campo de estudos sobre o trabalho docente a partir dos efeitos na formação de jovens pesquisadores.
\end{abstract}

Palavras-chave: práticas de pesquisa; docência; narratividade.

\section{Teaching narratives: sensitive dimension of the work of teachers and researchers}

\begin{abstract}
The article brings strands of experience in scientific research in psychology, where life in teaching, the everyday life and work in education are expressed in narratives produced by researcher and teacher. This is narratives experimentation, inspired by the thought of philosopher Walter Benjamin, as methodology of approach to the field of at work in education. The narrativity is a research-intervention mode which produces a field of affections between field researcher, resulting a contribution situated to the formation of research. Intercessors from the Clinic of French Activity and Institutional Psychology enter into dialogue on the work in school. This experience brings the sensitive perspective to the field of study about the teaching work from the effects on the training of young researchers.
\end{abstract}

Keywords: research practices; teaching; narrativity.

[...] recordara o tempo em que fui à escola pela primeira vez, lá nos meus oito anos de idade, lembro-me que minha idade era incompativel com o calendário letivo [...] fiquei muito triste por não poder estudar naquele ano. No ano seguinte [...] não faltava uma aula. Queria exatamente o quê, não sei; mas sabia que o conhecimento me dava novas possibilidades de sonhar, criar e inventar a vida (Diário de pesquisa: memórias de uma universitária, 2013).

O percurso do Núcleo de Pesquisa em Subjetividade e Política (NEPESP), da Universidade Federal do Espírito Santo, por meio do Programa de Formação e Investigação em Saúde e Trabalho (PFIST), realiza estudos movidos pela análise dos processos de trabalho. Na realização desses estudos se articulam diferentes processos formativos, as pesquisas se tornam campo empírico na formação integrada de alunos de graduação e pós-graduação, tornando indissociáveis práticas de pesquisa e de formação. Alguns efeitos destes processos formativos se evidenciam em textos como este. A aposta deste artigo é que as análises empreendidas pelo grupo de pesquisa, através do uso de ferramentas da Psicologia, se façam profícuas na problematização de metodologias que po-

^Este artigo é versão modificada do trabalho "Narrativas da docência: experimentando metodologias nas tessituras vida-subjetividade-trabalho", apresentado pelas autoras no VII Encontro brasileiro da Rede de estudos sobre o trabalho docente (Estrado): "Trabalho docente e Políticas de Responsabilização", realizado na Universidade Federal do Espírito Santo, Vitória, no período de 20 a 22 de novembro de 2013

$\star \star$ Endereço para correspondência: Universidade Federal do Espírito Santo, Centro de Ciências Humanas e Naturais, Departamento de Psicologia. Av. Fernando Ferrari, s/n, Goiabeiras - Vitória - Espírito Santo, ES - Brasil. CEP: 29060900. E-mail: betebarros@uol.com.br,jhanybrito@gmail.com, lenny.preta@gmail.com tencializam a experiência de vida na Educação, a partir da primazia de quem a vive, ou seja, operando com as análises vindas das experiências. Este ethos coloca as autoras diante de exercícios dialógicos desafiadores, tanto no meio acadêmico quanto nos contextos onde se capilarizam ações interventivas concretas.

Pesquisas ousam caminhos: constroem vias a cavar os espaços institucionais, inventam formas diferentes de composição com os ambientes e ritmos fora da Universidade. O desafio de promover um encontro qualificado com professores do rede básica de ensino se estende no momento da produção de narrativas como política de registro das pesquisas, já que para articular diferentes contextos nas produções é preciso abrir-se para estratégias de linguagem que abarquem estas experimentações. Assim, a formalização em escrita expressa um "labor" do pesquisador, constituindo um plano sensível da vida no processo de trabalho, que assume a vivacidade das experimentações escritas como importante dimensão da pesquisa e da produção de conhecimento.

Este artigo expressa problemáticas do trabalho de professores da rede pública de ensino, em meio às estratégias de escrita sintonizadas a comunicar as dificuldades e intensidades de um campo de pesquisa. Um processo formativo singular coloca os atravessamentos do processo de trabalho em análise, por meio de narrativas de vida docente, tramadas a partir de visitas, conversas e reuniões com trabalhadores de uma escola pública municipal. A pesquisa, realizada no período de um ano, investigou 
as articulações entre a produção de saúde e adoecimento na experiência destes educadores; o modo como percebiam o processo de educar; as alegrias e desafios que se expressam quando conseguem dizer algo sobre o processo de trabalho. A narrativa, então, constituiu forma de intervenção na qual os docentes, por meio do reencontro com a linguagem, testemunharam modos de dizer e narrar capazes de elaborar e reviver modos outros de vida na produção de escolas e práticas (re)inventadas.

O cotidiano escolar apresenta-nos muitas tensões relacionadas às questões sociais, como o aumento da violência, o uso precoce e abusivo de drogas, a vida possível para alunos em condição de proteção social, os menores assistidos. Nesse ínterim, a escola expressa o esforço diante das demandas pedagógicas engendradas nestas situações e é comum os docentes conectarem tais contextos à sensação de estarem sobrecarregados, de se verem sozinhos no trabalho e de se perceberem adoecidos. Todavia, com a pesquisa, se observa também sutis invenções do ofício, que apontam para a produção de mais companheirismo e outros compartilhamentos na resolução e encaminhamento dos problemas. A princípio, os professores reconhecem a necessidade de apoio na demanda por assistentes sociais e psicólogos na equipe escolar; ou na expectativa de melhoria da infraestrutura do trabalho ou ainda indicando que é preciso investir em outros modos de qualificação para os professores. Desde os primeiros contatos com o campo de pesquisa na escola de ensino fundamental, o que se encontra é um traço da vida contemporânea que se expressa na problemática do tempo e dos (contra)tempos da vivência do trabalhador do campo público.

Na busca do que se passa no cotidiano escolar, três pesquisadoras visitam a escola; muito ansiosas, procuram alguém para falar dos projetos de pesquisa. Conversamos sobre eles com a pedagoga que, solícita, já aponta como uma das causas de adoecimento de professores o barulho que ecoa dos alunos, que passam pelos corredores e descem as escadas. Em meios a compromissos e agendas a serem cumpridas, tempo é algo precioso: felizmente conseguimos vinte minutos na reunião de professores para apresentação dos projetos de iniciação científica (Diário de pesquisa: anotações do começo de uma abordagem à escola, 2013).

Os fios desta formação, que se dá na experiência de uma iniciação científica, apresentarão processualmente as narrativas da vida na docência, o cotidiano dos professores e nuances da organização do trabalho na escola. Necessariamente, articula-se nessa acessibilidade aos modos de viver o trabalho na educação, tessituras entre produção de subjetividade e práticas de pesquisa em ciências humanas, que se interessam pelo pensamento clínico de problematização dos processos de saúde (PASSOS; BARROS, 2012; BARROS, 2004). Aqui, são alinhavados temas de pesquisa como a narratividade; a docência no ensino básico e a democratização entre as experiências da escola e das políticas de pesquisa.

Outros estudos realizados no PFIST (UFES), ainda que não centrais neste artigo, certamente o compõem pelas transversais empíricas que ampliam os diálogos. Arranjos teóricos desdobram pensamentos no movimen- to engendrado às experiências das pesquisadoras. Falaremos de práticas narrativas que localizam no modo de escrita da pesquisa um caráter de intervenção. A pesquisa como prática intervém no campo, mas também na história de vida do pesquisador. Logo, a pesquisa produz um modo de "dispor a atenção" ao que é instituinte no viver a Educação, ao problematizar a formação, neste caso, inclusive a universitária.

Para estudos desta natureza, "o viver" é sempre uma investidura aberta em potencialidades analíticas, em produção de novas existências, pensando mais precisamente o campo de pesquisa na educação pública, as práticas que aqui nos interessam, são aquelas que se constituem como um combate às durezas, paralisias e assujeitamentos intermitentes em determinados modos de vida e de trabalho.

\section{Aberturas no trabalho docente: a "atividade" como vida}

No veio da Psicologia do Trabalho, algumas produções francesas nos são importantes interlocutoras, sobretudo as pesquisas realizadas em Clínica da Atividade (CLOT, 2010, 2011), operadora do percurso teórico-conceitual aprimorado pelo Centro de Pesquisa em Trabalho e Desenvolvimento (CNAN, Paris). Este laboratório perspectiva construir recursos metodológicos como acesso ao vivido nos contextos; elege o trabalho como espaço de construção de problemas científicos fazendo avançar os próprios campos teóricos e as teorias; e ainda realiza estudos que entrelaçam produção de conhecimento na direção da transformação das condições de vida do trabalhador. Através da crítica ao mentalismo, ao subjetivismo e aos especialismos, carregados de abstrações e generalizações pouco interventivas, as pesquisas em Clínica da Atividade (uma das modalidades em Clínicas do Trabalho) investem na construção de práticas assentadas em situações concretas, e na participação direta do trabalhador como sujeito que age, atribui sentido e pode transformar o contexto do trabalho.

Segundo Yves Clot (2011, p. 73): "No fazer, o sujeito age, portanto, também sobre as relações com os outros e consigo mesmo, graças às relações com os outros, mas, sem se limitar a este aspecto, e para fazer algo". Nesta perspectiva, o conceito de "atividade" traz interessantes desdobramentos às experiências desejosas de explorar temas laborativos, bem como traz a plurivocidade de sentido encarnada nas ações de trabalho. O conceito de atividade expande os horizontes produtivos conferindo atenção à dimensão construtiva do trabalho, onde atividade e produção se auto-engendram, localizando assim o trabalhador no meio produtivo, mas não o restringindo como produto do meio.

A atividade vive o contexto; o contexto de trabalho produz uma atividade, mas só a produz no sentido em que: um contexto é forjado pelo trabalhador para a existência da própria atividade. Não é diferente para o trabalho na Educação. A atividade do Professor faz-se imanente à vida ordinária e encarna a vida no trabalho com tudo o que se tem de amplo e transbordante. A atividade como vida é o que perspectiva uma tarefa, uma função, um papel, uma ação, reunião ou planejamento, 
e também o que vai além das prescrições que compõem esse fazer educativo. É parte da atividade uma gama de experiências, irrealizações, contratempos que a configura, a apresenta e a caracteriza desta ou daquela maneira, para este e aquele educador.

Falta tempo. O planejamento é insuficiente para correção e preparação das aulas. Provas são levadas e corrigidas em casa no final de semana. Quantas aflições em dar conta de corrigir... folhas e folhas ainda faltam ser corrigidas... e o professor, ao mesmo tempo, pergunta-se apreensivo: Por que o aluno não se empenhou em estudar? Porque ele não fez as atividades para casa? "O Professor não está aguentando", diziam alguns. Outros apontam culpa à família. Chega-se à conclusão, em tom de desabafo, que a culpa é da sociedade; e principalmente dos políticos que não investem na educação e saúde, e se preocupam unicamente em enriquecer-se com o bem público. Está chegando o prazo para repassar as notas dos alunos para a pedagoga. São os tempos da escola produzindo a atividade. O professor dá uma nova chance de o aluno recuperar a nota; repete a mesma prova, e o estudante, mesmo assim, não consegue tirar nota boa. E tudo isso, junto [...] (Diário de pesquisa: observações da aprendiz-pesquisadora, 2013).

Destacamos aqui três linhas constitutivas da atividade: 1) a indissociabilidade entre os aspectos afetivos e cognitivos no trabalho; 2) a não dualização (e sim, tensão) entre individual e social no trabalhador, e ainda 3) os efeitos singulares e estilizados da atividade são o que fortalece a dimensão coletiva, portanto, os coletivos de trabalho (CLOT, 2010). Assim, a atividade compreendida como sede de investimentos vitais do Professor, é o que pode perspectivar vias transformadoras de contextos e produtora de novas realidades. Se isso cabe, é porque as subjetividades não são tratadas como fechadas, amalgamadas em essências imutáveis, ou ainda, fadadas pelos determinismos estabelecidos. $\mathrm{O}$ professor que se aflige, ao preocupar-se com o aluno, com os investimentos públicos e os recursos sendo garantidos em Lei, constrói-se e modifica o trabalho sendo atravessado pela experiência dessas aflições, pelas irrealizações no cotidiano, através das inconformidades e da indignação; através também da repetição da prova e de tantas outras tentativas de hesito.

Dito de outra maneira, a atividade no trabalho da Educação é a produção de um meio de objetos materiais e imateriais e a produção de múltiplas relações que recriam meio de vida para exercer a docência e que, portanto, também fazem um professor exercitar modos de estar na vida. Por isso é possível afirmar que a vida humana é constituída nesta atividade que exerce o trabalhador. "O operar do trabalhador se confunde com o próprio processo de criação de si [...] criação de formas-subjetividades [...], ou seja, trabalhadores que no curso da atividade criam permanentemente na relação com os instrumentos de trabalho, reinventando-se" (BARROS, 2004, p. 99).

Por meio da atividade, o trabalhador constitui-se ao trabalhar, atribuindo ao trabalho um elenco de investimentos, nem sempre decifráveis pelas inúmeras cartilhas que modelam e normalizam as práticas no campo educacional. Nessa perspectiva, o que se apresenta como vida, como docência, como atividade é mesmo, e sempre, modular e processual; se recompõem; se reorganiza em ato, vivendo, agindo, educando...

O trabalho do Professor tem natureza viva, quer dizer, é uma experiência de vida sempre em processo, configurada de maneira ao mesmo tempo geral e singular; com afetações e ações que localizamos como compartilhadas, ou com características compartilháveis, mas também passíveis de estilizações, especificidades, peculiaridades que, ganhando visibilidade, podem nos ensinar muito, e a todos.

Em um dia o recreio ficou triste, tenso e sacudido. Professoras chegam até mim e dizem: 'Conte a ela! Conte a ela!' Um aluno tomando a dor do outro, ao ser chamado atenção pela professora, manda-a 'procurar um macho'. A professora indignada, desolada e com voz rouca, conta o ocorrido. Diz que está acostumada a ser mandada a tomar no cu. Mas isso para ela foi demais!

A família foi chamada à escola, o pai retruca dizendo que achava que of filho havia feito coisa pior.

O final de semana dela foi péssimo. Calada... Não contou nada ao marido, que se souber, exige a ela que saia do trabalho (Diário de pesquisa: mapeando o que constitui o trabalho do professor, 2013).

Ao desenvolvermos atenção à atividade docente, aguçamos as pesquisas em educação ao interesse pelas produções de subjetividade, pelas relações, atravessamentos, pertencimentos e efeitos do trabalho sobre a docência, portanto, sobre a história de vida do Professor, na processualidade que se dá a reconstrução de sua trajetória profissional. Barros, Ronchi-Filho e Rosemberg (2011) reiteram essa direção. Para os autores, uma análise do trabalho só se efetiva quando a pesquisa, os recursos usados, a direção de um processo é cogestada no caminho, possibilitando o engajamento do trabalhador na análise de sua condição de trabalho, através do tempo e dos modos de caminhar da pesquisa. Isto implica um desafio e uma sutileza: ao mesmo tempo em que desenvolvemos atenção ao que constitui processo de trabalho, os Professores também devem fazê-lo. Pesquisas que prezam pelo caráter interventivo, quer dizer, modificador de realidades, demandam a experimentação de metodologias que possibilitem com que os trabalhadores se encontrem com suas experiências em um intento analítico, quer dizer, que os professores "[...] se libertem o quanto possível de seus modos habituais de pensar e de falar de suas atividades" (BARROS; RONCHI-FILHO; ROSEMBERG, 2011, p. 196).

\section{O professor e a "expressão da atividade": diálogos com a metodologia de pesquisa}

Uma prática de pesquisa contribui para que o trabalhador se reencontre com o que se tornou habitual. $\mathrm{O}$ método lança o trabalhador em um movimento que desnaturaliza atuações, soluções costumeiras, violências banalizadas. Tudo isso, deve, mais do que ser constatado e mapeado pelos pesquisadores, ainda que "denúncias" feitas pelas pesquisas possam produzir estratégias políticas. Contudo, urge que os problemas e impasses do trabalho sejam colocados na mesa, por dispositivos que 
possibilitem ao trabalhador um confronto com seus contextos, recursos, formações, implicações, e é nisso que localizamos a potencialidade analítico-interventiva de um método. Ou seja, quando se exercita nas estratégias de pesquisa a saída dos esquemas explicativos representacionais, generalistas, categorizadores, aqueles ordenadores do viver que comumente espera-se da labuta de nós, especialistas da academia.

Diferente desta última direção, o convite aqui é deslocar a intensidade do saber, e da produção de conhecimento, para o trabalhador e seu campo relacional, saindo das heranças transcendentais que impedem com que o contexto fale por si; que dificultam com que as empiricidades a si se remetam; o que notadamente ampliaria as forças disruptivas capazes de produzir conexões significativas ao sentido do trabalho.

Nesses termos, analisar o trabalho pode ser uma experiência que se faz incluindo os modos de pesquisar que se exercitam em um esforço "anti-soluncionista" e "anti-interpretacionista”. Criar condições metodológicas para a análise da atividade docente convida-nos a fazer um exercício de pensamento pelas descontinuidades e assimetrias na experiência de um pesquisador. Localizamos, por isso, nos instrumentais de pesquisa, nesta tensão pesquisa-campo, considerando nos espaços relacionais, pequenas transgressões com o estabelecido capazes de faiscar invenções nos modos de pesquisar, desejar e falar - como nos alerta Rodrigues (2012).

Chama-se a atenção, que este recurso simples e não banal, a experiência do diálogo pela confrontação com a voz do Professor em agonística, e fazendo vibrar um detalhe no vivido, deve ganhar espaço na metodologia como um chão acolhedor dos exercícios de análise do e no trabalho. Investir em estratégias dialógicas e na especificidade (e potencialidade) de cada conversa é relevante, sobretudo, pela onda de práticas de sucateamento das políticas públicas, que fragilizam os coletivos de trabalho com a tática do isolamento do trabalhador e da invisibilidade dos problemas cotidianos. Neste esteio, vivências educativas tendem a reduzir as problemáticas a privatizações, que encontram na perspectiva psicológica-intimista recursos de responsabilização e/ou culpabilização individuais, corroborando, cada vez mais, com o peso das experiências de adoecimento. Temos aqui um importante sinal de alerta! "Naquele dia: Foi um tumulto, todos queriam falar ao mesmo tempo; [...] e mesmo o tempo já se esgotando, onde alguns professores precisavam sair para dar aula em outra escola [...]" (Diário de pesquisa: a contribuição da conversa qualificada no cotidiano do trabalhador, 2013).

Não há zona de conforto nas estratégias de individualização e produção de sofrimentos, crescentes com a fragilização da vida no trabalho. Os professores nem sempre são cúmplices dos desmandos e da perda de autonomia, tão alargados na gestão do cotidiano escolar. Tampouco apenas se acomodam nesta rotina de duplas e triplas jornadas de trabalho. Se a dimensão da sobrevivência assim os exige, não se pode negligenciar um campo problemático nessas condições cada vez mais estruturantes. Atentos à outras sutilezas, percebe-se o quanto os professores sabem dos incômodos e dores que margeiam os queixumes transmitidos pelos largos estudos no campo da educação. Meio a isso, apostamos que é na fagulha intensificada pelas brechas do encontro pesquisador-escola, que instantes podem se abrir à escuta das inconformidades; do pedido de alianças e da criação de novas estratégias no trabalhar que sejam menos sofridas e isoladas.

Gostaríamos de ressaltar este ponto problemático: os efeitos sutis da leitura do trabalhador sobre o processo de trabalho na escola; as dimensões imateriais que constituem a docência e o plano afetivo-inventivo do ofício do Professor ainda escapam dos métodos convencionais de pesquisa em educação. Passam, muitas vezes, ao largo do debate acadêmico. Mas, estamos em vias também de afirmar que são estes atravessamentos no fazer do educador, que podem provocar outros acessos ao que é experimentado no trabalho, pouco presente nos questionários diretivos e globalizantes, nos levantamentos estatísticos indiretos ou nas catalogações de Leis e Normas operacionais que tanto regem o sistema educativo.

"Conte a ela" - frase proferida na escola e endereçada à jovem pesquisadora - é ânsia por expressividade!

"Todos queriam falar na escassez de tempo" - é um convite feito à pesquisa acadêmica para a composição do diálogo, evidencia também a sua contribuição no contexto de vida do trabalhador. Este, então, formula um pedido de composição com a presença de uma pesquisa que possa estar inteira, portanto, que também não seja absorvida pelo tarefismo contemporâneo, quando desenvolve seus procedimentos junto aos trabalhadores. Estamos em vias de formar outra corporeidade e disponibilidade por parte dos pesquisadores, para que a própria pesquisa seja uma prática de interesse de participação por parte dos trabalhadores de âmbito do serviço público municipal.

Nessa correria que faz o trabalhador se dividir em contratos e escolas, há índices de que as pesquisas acadêmicas têm efetiva contribuição aos territórios e realidades municipais. Índices que fortalecem o compromisso da Universidade Pública na revisão das posturas diante dos territórios, a partir, inclusive, do questionamento aos modos como os pesquisadores se conectam aos espaços-tempo das políticas públicas. Por isso mesmo: rodas de conversa; comunidades ampliadas de pesquisa; realização de fóruns locais e aquecimento de redes loco-regionais (dispositivos pouco habituais no campo das práticas em educação) têm sido de grande investimento para o coletivo de pesquisadores do PFIST. Isto, porque reconhecemos que os professores procuram audiência sensível para os acontecimentos que atravessam seu trabalho. Também, porque o cotidiano escolar indaga o cientificismo que elimina os rastros, as falas, as correrias e confusões dessa ampla tessitura de vida constituída na escola.

Então, o que esta pesquisa entende por plano metodológico encarna o compromisso público da produção de conhecimento, na perspectiva onde intervir é parte do conhecer; quando construir registros e escritas com os ritmos do campo, produz modificações no estatuto da 
própria pesquisa, mas também é oportunidade de atenção e derivas na relação do trabalhador com sua atividade. É importante salientar que este tipo de pensamento vê importância, menos no resultado a ser obtido, e mais no que se anuncia durante o processo. O caminho do pesquisador, o encontro com o campo e os participantes da pesquisa, bem como a forma compartilhada de produção de conhecimento - são relevantes neste tipo de plano metodológico, logo, devem ser estruturantes também na formulação das escritas sobre pesquisas. É nessa via que se dão as múltiplas formações: práticas de pesquisa engendradas nas práticas de trabalho.

Escola de encontros, reencontros, desejos, sabedoria, fé, perdão, fuga, violência, medo e drogas. Na escola muito relato, desabafos, angústia por não encontrar formas de resolver os problemas de uma sociedade que acha que a educação resolverá tudo. A demanda é gigantesca e a escola sozinha não está dando conta disso (Diário de pesquisa: o trabalho do pesquisador tem implicações, 2013).

Nossas pesquisas tateiam práticas dialógicas com o sindicato, problematizando suas correlações com a gestão do trabalho na escola (BONALDI; BRITO; BARROS, 1995). Também já experimentamos pesquisar junto às Secretarias de Educação, onde o estreitamento com o cotidiano escolar é sempre um desafio. Modos de gestar a escola e de organizar os serviços públicos de apoio/atendimento ao professor, em suas correlações com a produção de adoecimento e cuidado, são do interesse destas pesquisas no território municipal (BARROS; RONCHI-FILHO; ROSEMBERG, 2011). O arranjo das políticas públicas; os sistemas de representatividade do trabalhador; as redes assistenciais que se encontram com o adoecimento docente, tudo isso, evidencia as muitas pressões a que a educação se encontra e onde o Professor se estica.

Há uma persistência em examinar, na atividade do Professor, a docência como uma experiência e, ao fazê-lo, tem-se modulado os meios de intensificação dos encontros e diálogos com os trabalhadores das escolas. Ratificamos: o trabalho de pesquisa na dimensão da produção de subjetividades, de acuidade aos modos de viver a educação, evidencia que os gestos do trabalhar, desta ou de outra maneira, efetivam modos de produzir a relação si-mundo. Ter como estratégia o adensamento da "expressão da docência" é urgência de outra forma de enunciar o trabalho na educação, localizando outros elementos e frações de enunciações empíricas que passam pela voz dos professores.

Mas como as pesquisas podem se surpreender com o que encontram, produzindo conhecimento pela não obviedade do que já é constatado? Como perspectivar os dados, não em uma coleta, mas em uma produção, conjunta, parceira e solidária? Que metodologias, afinal, possibilitam produzir análises com o trabalhador, compondo falas, produzindo dialogia e perturbações no hábito do que faz sofrer e adoecer?

\section{$O$ pesquisador: narrador que transmite algo da experiência na docência}

O narrador-pesquisador, quem é ele? Quem é este que, dos relatos do professor, narra com a vida, narra com a expe- riência do professor, com a escola, e os alunos? (Diário de pesquisa: indagações de uma pesquisadora na formação do método, 2013).

Trazemos agora ao artigo, a figura do narrador, um intercessor desta experimentação de pesquisa. A formação em Iniciação Científica possibilita o encontro com os processos; as temporalidades e especificidades do fazer científico. Este momento ímpar na formação acadêmica não se mostra interessante, apenas, pela cadeia formativa sucessiva que poderá se estabelecer: iniciação científica, mestrado, doutorado. Mais do que isso, permite ao estudante uma experiência de construção deste corpo-pesquisador que operará com as teorias a partir de uma aprendizagem inventiva, que só pode se dar no processo de condução de uma pesquisa como experiência singular (KASTRUP, 2008).

Neste estilo de produção de conhecimento, o método também surge como potencialidade de aprendizado encarnado em meio à criação de estratégias para ocupar os espaços; ao compor com os outros; ao criar vínculos e relações no desenvolvimento de uma modalidade de escuta e observação diferenciadas. Na trajetória de uma experiência situada, emerge um pesquisador-narrador que se prepara durante a pesquisa para construir ações/ momentos com os professores, aprendendo com a experiência com as palavras, se lançando no plano sensível que atravessa o trabalho docente.

A pergunta sobre "quem é ele, o pesquisador" passa a ser uma problemática que se conecta à "como constituir-se um pesquisador na educação" construindo uma pesquisa-intervenção como método que auxilie o processo de pesquisa-formação. A problemática empurra-nos um pouco mais pelas veredas do método, quer dizer, uma experimentação forjada a fim de configurar intervenções nos modos de tratar o trabalho docente que produza efeitos para além do trabalho do Professor.

Os caminhos com a Política da Narratividade, como um campo e um recurso a pensar esses meios da produção de conhecimento pela "atenção ao que se processa", valida encontros, desencontros e assimetrias da vida, operando indistintamente com as assimetrias da linguagem, quer dizer, tratando conceitualmente a expressão de como se constitui as coisas durante o processo de pesquisa, e posteriormente, dando relevância as formas de transmissibilidade - quer dizer, as maneiras de narrar a experiência do que se passa em uma formação pela pesquisa: "A narrativa é a experiência de contar com o outro e não do outro" (Diário de pesquisa: notas da pesquisadora, 2013).

Dito de outra maneira, a narratividade como um trabalho de composição, faz emergir acontecimentos meio à produção de subjetividades. A produção de "modos de ver e sentir a vida da pesquisa" é costura da memória viva de sua trajetória. Assim, a pesquisa perspectivada como composição produz existências coletivas, quando pesquisador-narrador-professor se torna dimensão comum na partilha de um encontro e/ou conversa. A experiência passa a expressar uma transitoriedade histórica, 
quer dizer, um movimento de constituição no texto do que é vivido, do que pode ser partilhado, o que pode ganhar grafias existenciais no chão da ciência: uma passagem pelo corpo de nós, pesquisadores, embriagados de processos formativos com o mundo; marcas na pele de outros, os sujeitos de pesquisa, aliviados de poder encontrar expressividade ao que vivem.

O plano metodológico da narratividade é constituído como uma prática de pesquisa que trata as pulverizadas conexões sociais, os engendramentos conceituais, os confrontos perceptivos e estranhezas sinestésicas, construindo uma forma de dizê-los. Ao encarnar-se no corpo do pesquisador-narrador, e na efetivação da produção de narrativas dos momentos da pesquisa, a narratividade dá força e inteligibilidade em meio da produção de realidade - um desafio para quem escreve, pois processos são acolhedores de diferentes corpos, meios de vida e misturas significativas.

Como um diagrama (DELEUZE, 2005), esse modo de ver e dizer que responde a uma política diante do texto, ou seja, certo modo de evidenciar que denota uma direção ético-política, dá visibilidade à complexidade própria da vida; encontra subterfúgios para expressar; produz ferramentas tanto para cuidar do processo de pesquisa, quanto para desenvolver recurso à motricidade do plano analítico. Afirmamos a narratividade, este trabalho com a experiência e o dizer; com o pesquisar e o escrever; como exercício ético que ajuda a configurar um corpo formativo na tessitura empírica da escrita de uma experiência. Escrever "sobre pesquisa", aqui, deriva-se junto com a experiência de narrar a vida na docência do ensino fundamental (BENJAMIN, 1994).

Em recente coletânea, Oliveira et al. (2010) organizam artigos de diferentes universidades brasileiras que exercitam o trabalho com as narrativas (de fotografias, documentos históricos, romances...) como modulação na ciência hegemônica. Os autores confrontam nessa coletânea a objetividade; a métrica; a compreensão obtida pelo padrão de repetição e semelhança, bem como problematizam o alcance explicativo linear e causal. Este movimento crítico estabelece abertura a exercícios de pesquisa na educação que, como o nosso, consideram a dimensão imaterial, sensível e não linear do viver a docência. Exercícios, portanto, que cuidam em não fazer uso da linguagem para petrificar o processo de produção de conhecimento, transformando-o em objeto científico desvitalizado, diferentemente, usam a labuta com o tempo e as historicidades para valorizar a organicidade dos campos problemáticos.

Nesse sentido, a narrativa é um recurso a dar vivacidade e motricidade à pesquisa. Um dos objetivos desse trabalho é fazer emergir realidades epistemológicas diferenciadas, a partir da operação (oral e escrita) com os universos caóticos, com a multiplicidade constitutiva das práticas sociais, bem como operar com intensidades textuais e imagéticas. A aliança política, aqui, foi aproximar as práticas de escrita da trajetória de vida do Professor ao construir sua história no trabalho, comumente escamoteada das normas da cientificidade moderna, purificadora das produções e preconizadora da hierarquia entre os saberes - o que alimenta separações entre "teoria e prática" - "vida e texto" - "trabalho e expressividade".

Na escola muita conversa com o professor, a sala dos professores foi o palco de vários relatos e desabafos que precisam ressoar os muros da escola. Os professores ansiosos queriam e precisavam falar. A gravação era algo muito importante e o recado precisava ser passado na integra, sem corte! (Diário da pesquisa: atenção da pesquisadora à aliança feita com os trabalhadores, 2013).

"Sem corte" é ouvido como alerta ao desdobramento do trabalho do pesquisador por meio da função de transmissibilidade do conhecimento. Cortes e processos de edições são o que comumente se faz nas pesquisas, em posturas onde o pesquisador conclui dizeres, afirma e interpreta.

Esta prática herdeira de uma ciência apartada das misturas entre dizeres costuma dar provas de deslealdade pendendo o saber, a importância e a legitimidade ao discurso científico, em detrimento do dizer da experiência que o trabalhador pode, deseja e pede para evidenciar. Será possível exercitar o diferir deste modo? É possível estender este tipo de exercício dialógico às modalidades de análise dos artigos e relatorias de pesquisa? Qual política de escrita então empreender?

\section{Narrar com os fragmentos: usando cacos de uma história plural}

O cuidado no trato de uma experiência de vida como meio de trabalho para outros traz, paradoxalmente, a dimensão não particularista ao debate. Para Yves Clot (2010) o instrumento coletivo da atividade coloca os recursos de uma história coletiva a prosseguir o gênero profissional. Olhando a docência como gênero (campo de experiência que oferece recursos à vida de um professor) encontra-se uma memória transpessoal, provisória, mutável, vivificando-se nos gestos do trabalhador. Coaduna, que cada Professor, cada trajetória, cada experiência, tem a potencialidade de renovar os recursos partilhados, “criação estilística no gênero profissional”, quer dizer, produção de força motriz ao desenvolvimento do trabalho na educação pública.

Uma história na docência, percursos na educação, estratégias desenvolvidas como recursos de um trabalhador na transformação da experiência de vida-trabalho abrem, então, inesperadas conexões, reflexões e análises que potencializam o desenvolvimento do gênero profissional, ou seja, é apoio ao trabalhador naquilo que empreende com a sua vida. Desse modo, uma vida pode estar a serviço do trabalho das vidas na educação, quando problematizada pela impessoalidade das práticas, sendo, portanto, cada expressão, uma chance de sintonia, partilha e coletivização de memórias, trajetórias formativas e recursos afetivo-políticos no e para o trabalho. A magia do narrar contagiava o outro a também contar a própria experiência, ninguém queria ficar no anonimato: "Era importante expor a opinião e debater sobre o dia a dia na escola" (Diário da pesquisa: narrativa dos efeitos da pesquisa, 2013). 
Trazemos, neste momento derradeiro do artigo, um fragmento de narrativa produzida no encontro dialógico entre pesquisador-professor na escola, compondo com os registros do trabalho metodológico, no objetivo de elucidar processos de formação-pesquisa-trabalho a partir da expressão da atividade do professor, e que, por isso, pode contribuir à expansão de sentidos sobre o trabalho na educação.

Trata-se de um oportuno registro, feito com a simplicidade daquilo que é investimento vital do professor; feito com a força do ínfimo emanada das relações professor-aluno; professor-professor; professor-família, professor-Secretaria de Educação. Trata-se, ainda, de vermos uma fração de tempo atualizando a docência como herdeira de múltiplos percursos na vida, a docência herdeira de uma tradição, o gênero profissional. Eis uma narrativa construída na escola, pelo encontro com uma docente entre outros. Professora há dezenove anos!

Peço a experiência para contar-me o caminho, o percurso e trajetória do trabalho na docência.

[Um tempo se abre. Lacuna entre os dizeres automatizados. Silêncio].

Fica pensativa e um pouco sem jeito. A expressão facial mudou, os olhos brilharam. Passou um filme em milésimos de segundos ao responder o pedido. Não sabia como começar. Percebe-se que isso toca os docentes que ali estavam na partilha do vivido, no momento daquela entrevista.

[As lacunas indicam a força da história, motora do gesto afetivo-cognitivo que é a experiência do narrar implica. Indicaria também desconforto em dizer de si? Seria algum tipo de recusa?].

Pediu-me que no primeiro momento não gravasse... Começa então a contar uma história de vida traçada na Educação. Memória de entusiasmo, no início [...] depois, diz não saber como isso se perdeu. Algo se perde com o passar do tempo.

[A vida acessada fora da objetividade e do tecnificismo é, por vezes, falha em soluções e respostas; vive lapsos, vive o não-saber. Nas escanções do tempo, do pensamento e do conhecimento já sabidos, o que desistrumentaliza o trabalhador de dizeres prontos surge no intervalar entre as palavras, no vazio delas. A memória afetiva cria positividades ali onde a racionalidade do já conhecido falha e abre espaço; no sucedâneo do tempo cronológico emerge o atravessamento de uma lembrança].

Gostava mesmo de fazer poesias e poemas, tinha até um caderninho, no qual um amigo 'roubou'e, depois fez uma música. Conta que no aniversário da irmã preferida, fez um poema que deixou de presente a felicidade. Emociona-se. De família do interior do Espírito Santo; oito mulheres e três homens, essa professora de 'veia poética', graças ao pai e a irmã mais velha, relembra quando a irmã foi estudar na Capital e, voltava para passar férias em casa. Era muito divertido, pois brincávamos de escolinha com os irmãos mais novos, e foi assim que aprendemos a ler e escrever.

[Narrar oportuniza a emergência de um instante tal que a poética do cotidiano começa a forjar uma formação no corpo, como didática, reconstituindo a docência].
O pai um contador de 'causos' e histórias [...]. Após o jantar juntava a família, as horas e a vizinhança, que a esta altura, reveza com o pai a disputa de quem narrava a melhor história, com maior capacidade de surpreender. Como ficava muito tarde para o vizinho distante voltar para casa; não se tinha outro jeito. Dormia na casa do compadre. 'Sabe como é uma mente de uma criança [...] eu imaginava e viajava nessas histórias'. E tarde, quando as crianças não aguentavam, e cochilavam; resistiam em ir para a cama, dizendo que não estavam com sono; [...] queriam ouvir histórias encantadas [...].

[Tomar uma conversa como espaço narrativo apresenta os tempos outros, neste caso, que introduzem o mundo do curiosar. Gesto de um ofício. Trabalho do professor com um tipo de conhecimento que faz sonhar, criar e inventar a vida: como a memória da estudante trazida na epígrafe deste artigo].

A professora estudou na Escola Técnica da capital e o curso de Edificações a leva como projetista ao estágio na Vale do Rio Doce. O sonho de "estudar línguas" ajuda a bifurcar o caminho depois do desentendimento com o chefe; o término do estágio foi pela falta do espaço autônomo para a projetista. $O$ sonho antigo, somado ao desentendimento, cria mais uma transitoriedade no insulto que experimentava com alteração da atividade de estágio para a função de secretária. Uma tensão. Na luta, persiste o sonho! Faz vestibular para Letras português e o gosto pela Universidade a leva ao re-começo da história de ensino-aprendizagem - começou a trabalhar como professora de designação temporária em uma escola. Na primeira experiência, elaborava aulas de teatro, poesia e músicas para alunos aprenderem determinada matéria de forma descontraída. Durante a conversa, tira da bolsa um papel velho e amarelado com o tempo, onde estava escrito 'o rap das conjunções coordenadas'. Lê e, imediatamente, as outras professoras pararam o que estava fazendo, para ouvi-la.

[Momento raro na escola, onde a vida de cada um toca a vida de todos: olhar e atenção dos outros; composição fina entre os professores].

Com os olhos ainda brilhantes, se dá conta do que já havia feito; do tempo que partilhava aula com a professora de artes. Que não se importava em tirar dinheiro do próprio bolso para realizar oficinas de leitura e passeio com os alunos. Guarda fotos e mensagens dos alunos desde que deixou aquela escola. Depois do concurso do município vizinho, como professora efetiva, deixa outras experiências, contratos e vínculos. Os alunos fizeram uma festa de despedida em um dia de tristeza, e ao mesmo tempo alegria. Havia carinho dos alunos [...]. [...] ainda mais nostálgica, comenta que não sabe como perdeu a habilidade poética. Será por quê? Questiona-se.

[Valiosa abertura, de intervalo e de descontinuidade. Momento de reencontro do professor com os feitos e interrompidos; produção de sentidos para a vida na educação e para a constituição de si no mundo do trabalho. É importante o que se positivará pelo trabalho da memória; o que se atualizará como intensidade das mudanças, dos novos tempos e dos desafios no viver a docência]. 
Logo vêm as dificuldades quanto à relação de professor e aluno.

[E será qual relação com a poética-como-didática?].

Lembra-se do clima bom de amizade e harmonia entre professores e alunos. Agora isso é passado. O horror, o medo do aluno, o toque de recolher, o carro danificado são angústias e tensões que faz-se como expressão. O peso deste momento é então amenizado pela sobrevivência narratológica. Relata... um dia desses... Na sala de aula, alunos atentos assistindo a aula de conjugações de verbos. Matéria dificil... coordenador entra e interrompe a aula para dar um recado. Alunos reclamam! Essa é uma fagulha de felicidade e surpresa... Socorro feito pela memória. A professora não acredita na cena ocorrida. Os alunos pediam a aula.

[As intensidades do trabalho insistem em sinais de irrealizações e frustrações da atividade; modela didáticas; movimenta currículos e cotidianos].

O tempo é curto para criar. O tempo de planejamento é insuficiente para organizar atividades diferentes e estimuladoras de aprendizagem. E o almoço é acelerado. É preciso chegar a tempo na outra escola. E... Resultado: professora cansada. Já pediu aposentadoria proporcional aos anos trabalhados.

[Desistência?].

Não conseguiu ser atendida na solicitação.

[Que desdobramentos?]

Surge o encontro com outra professora, no momento da entrevista, o que abre espaço para a crítica de duas professoras novatas, 'muito boas e universitárias'. Diante de tantas 'qualidades', elas recusam dar aula para alunos de comportamentos dificeis e complicados. Reafirma o neologismo: 'universiotárias'; junção de universitária com otária. O cansaço se mostra na forma-dureza-ressentimento. Nada de espaço à criação. Uma nova palavra e afeto de desvalorização frente à situação. Afeto que chama outro afeto para o cenário do trabalho docente. Despeja então ironia... aguça o senso de justiça ao lembrar professores da Secretaria da Educação, que apontam "corpo mole" dos professores de sala de aula. O deboche é o que surge na comemoração e no sorriso, ao ouvir a notícia de que uma das professoras da Secretaria volta ao trabalho na sala de aula. Sala de aula agora é punição. Bem Feito: é a comemoração que escande a narrativa" (Diário da pesquisa, 2013).

\section{Finalizando o ensaio}

Walter Benjamin (1994, p. 201) nos afirmaria, na clássica obra de 1936, O narrador, que "estamos pobres em experiência comunicáveis". Depois da Guerra, os soldados voltavam silenciados, mudos. Nada tinham de uma experiência digna a ser contada de boca em boca. Perde-se a dimensão de acontecimentos a serem transmitidos de geração em geração. $\mathrm{O}$ surgimento do modo de vida capitalista e a primazia da informação, com isso, a valorização de um presente de instantaneidades, é terreno para esse quadro onde não se há o que comunicar em suas intensidades longevas. Cabe, sempre menos, que histórias sejam contadas e ouvidas, entre trabalhadores, pesquisadores, sujeitos históricos.
Mas a produção do trabalho artesanal com a narrativa, paradoxalmente, dá forma à grande matéria narrável, e proporciona a ligação secular entre a mão e a voz, entre o gesto e a palavra, ou seja, ligação entre a atividade do professor e sua expressão - mundo fundado pelo trabalho ativo da lembrança e da memória. Surgem nesse veio, histórias perspectivadas e tecidas como abertas, inconclusas, portanto hábeis a continuar de outras formas, podendo, por vezes serem contadas e recontadas por outros.

Nas diversas maneiras, uma narrativa se define por provocar sentidos outros, que são também os desdobramentos como ação do pensamento. O filósofo alemão defende assim, com a teoria da narração: prática histórica que fuja aos nexos causais frutos de temporalidades hegemônicas. O que, nesta pesquisa, ajudou a confrontar esta lógica foi a criação de estratégias questionadoras dos modos habituais de pensar ciência e método. Narrar uma experiência, e como trazido ao longo deste artigo, narrar a formação no processo de encontro dialógico com o professor, possibilita o exercício de dispositivos que se aliançam a um plano intensivo, o que força, necessariamente, "[...] um abalo no tempo, uma interrupção nos relógios, uma ruptura com os hábitos mentais da burguesia" (FERREIRA, 2011, p. 126).

A crítica a uma história burguesa e progressista de grandes feitos e glórias, abre a atenção do pesquisador para o trabalho minucioso e inglório com as franjas da memória, atenção também aos lapsos temporais, porque não dizer, atenção aos cacos fragmentários de uma história profissional (GAGNEBIN, 1994). Nas margens de uma pesquisa de iniciação científica, a historicidade de interesse é a que possibilita àquele que narra tencionar história individual e história de um coletivo, ou seja, o gênero profissional docente.

Vale destacar: “[...] é preciso coragem e audácia de saber para perceber que um processo do qual os homens fazem parte coletivamente é um ato de coragem a realizar pessoalmente" (FOUCAULT, 2005, p. 338). Narrar foi para os professores meio de observação do que estão fazendo com as próprias vidas, ou seja, uma oportunidade conferida pela pesquisa de olhar, ouvir e se constituir de outros modos durante a narrativa. Essa experiência produz subjetividade porque é exercício de um "[...] ethos filosófico que seria possível caracterizar como crítica permanente de nosso ser histórico" (FOUCAULT, 2005, p. 345). Narrar ajudou a problematizar parâmetros ético, estético e político do educar, e do percurso de vida na docência. Mais do que um diálogo com a Universidade e o pesquisador, o professor pôde produzir atenção diferenciada a sua experiência habitual de trabalho.

Diríamos ainda que esta pesquisa acolhe a participação do professor nos rumos do pensamento. A escrita como produção do pesquisador expressa o impacto de como o professor vive sua atividade. Narrar tem esse efeito clínico na escola, produção de surpresas e desvio, a partir da oportunidade sustentada para que inquietações se expressem. Como ação e sentido são indissociáveis, poder narrar impasses do cotidiano faz vacilar as certezas e naturalizações sobre a atividade. 
Narrar então transforma o contexto do trabalho porque este guarda uma função construtiva. $\mathrm{O}$ cotidiano onde a raridade de vínculos impera, quando isolamento e individualizações se exacerbam, viver o 'compartilhar' coloca a necessidade histórica no cerne do ofício (FERREIRA, 2011). "Não estamos mais sozinhos", ou seja, existe uma escuta e aliança porque há democratização como estratégias do trabalho de pesquisa. Professor e pesquisador se permitem inventarem-se, juntos.

$\mathrm{O}$ instante, a raridade e a autonomia se aliançam para afirmação da vida. É a vida que dá contornos a essas experiências de trabalho-pesquisa. A formação do corpo-pesquisador preparou uma jovem da iniciação científica para o encontro com diferentes forças, temporalidades e intensidades dos modos de vida, modos de pesquisar. Há efeitos formativos nessa entrada no campo, que é conquistada no encontro e pactuada na relação pesquisador-escola. Enfatizamos que a pesquisa como plano de composição producente pôde se fazer por ter criado essa sintonia que oportunizou o contar histórias. Aprende-se sobre a organização administrativa e pedagógica da escola, mas também se aprende com as angústias e (in) realizações do trabalho.

Pesquisar, neste sentido, perspectivando a narratividade, pede mesmo uma formação, um corpo outro que é preparado no encontro dialógico, na democratização de ações e vozes a ocupar o espaço não burocrático da escrita. Assim, o corpo-pesquisador alinhava sua produção conectiva com mundos menos essencializados e mais abertos às sensibilidades que ajudam a registrar a vida de uma pesquisa. Perseveramos com pedagogias poéticas (LINHARES, 1995). Nosso desafio é uma democracia cognitiva. Permitir a polifonia nos exercícios metodológicos que empreendemos.

\section{Referências}

BARROS, M. E. B.; RONCHI-FILHO, J.; ROSEMBERG, D. S. (Org.). Trabalho docente e poder de agir: clínica da atividade, devires e análises. Vitória: EDUFES, 2011.

BARROS, M. E. B. Modos de gestão e produção de subjetividade. In: BARROS, M.; ABDALLA, M. (Org.). Mundo e sujeito: aspectos subjetivos da globalização. São Paulo: Paulus, 2004. p. 93-114.

BENJAMIN, W. O narrador: considerações sobre a obra de Nikolai Leskov. In: Magia e técnica, arte e política. 7. ed. Tradução de Sérgio Paulo Rouanet. São Paulo: Brasiliense, 1994. v. 1, p. 197-221. Obras escolhidas.

BONALDI, C.; BRITO, J.; BARROS, M. E. B. Saúde e trabalho nas escolas: a ação do sindicato de professores do ES. Cadernos de Pesquisa em Educação, Vitória, v. 15, n. 30, p. 72-98, dez. 1995.

CLOT, Y. Introdução: questão de ofício. In: Trabalho e poder de agir. Belo Horizonte: Fabrefactum, 2010. p. 1-44.

CLOT, Y. Clínica do trabalho e clínica da atividade. In: CLOT, Y.; BENDASSOLLI, P. F.; SOBOLL, L. A. P. (Org.). Clinicas do trabalho: novas perspectivas para a compreensão do trabalho na atualidade. São Paulo: Atlas, 2011. p. 71-83.

DELEUZE, G. Do arquivo ao diagrama. In: Foucault.

São Paulo: Brasiliense, 2005. p. 13-33.
FERREIRA. M. F. Walter Benjamin e a questão das narratividades. Mnemosine, Rio de Janeiro, v. 7, n. 2, p. 121133, 2011.

FOUCAULT. M. O que são as luzes? In: MOTTA, M. B. (Org.). Arqueologia das ciências e história dos sistemas de pensamento. Rio de Janeiro: Forense Universitária, 2005. Coleção Ditos \& Escritos, v. 2, p. 335-351.

LINHARES, C. Democracia cognitiva, poética e formação docente. Cadernos de Pesquisa em Educação, Vitória, v. 16, n. 32, p. 154-183, dez. 1995.

GAGNEBIN, J. M. Prefácio: Walter Benjamin ou a história aberta. In: BENJAMIN, W. Magia e técnica, arte e politica: ensaios sobre literatura e história da cultura. 7. ed. Tradução de Sérgio Paulo Rouanet. São Paulo: Brasiliense, 1994. v. 1, p. 7-19. Obras escolhidas

KASTRUP, V. A cognição contemporânea e a aprendizagem inventiva. In: KASTRUP, V.; TEDESCO, S.; PASSOS, E. Políticas da cognição. Porto Alegre: Sulina, 2008. p. 93-112.

OLIVEIRA, I. B. de. (Org.). Narrativas: outros conhecimentos, outras formas de expressão. Rio de Janeiro: FAPERJ, 2010.

PASSOS, E.; BARROS, R. A cartografia como método de pesquisa-intervenção. In: PASSOS, E.; KASTRUP, V.; ESCÓCIA, L. (Org.). Pistas do método da cartografia: pesquisa-intervenção e produção de subjetividade. Porto Alegre: Sulinas, 2012. p. 17-31.

RODRIGUES, H. B. C. Analisar. In: FONSECA, T. M. G.; NASCIMENTO, M. L; MARASCHIN, C. Pesquisar na diferença: um abecedário. Porto Alegre: Sulina, 2012. p. 37-39.

Recebido em: 31 de março de 2015

Aceito em: 23 de junho de 2017 